
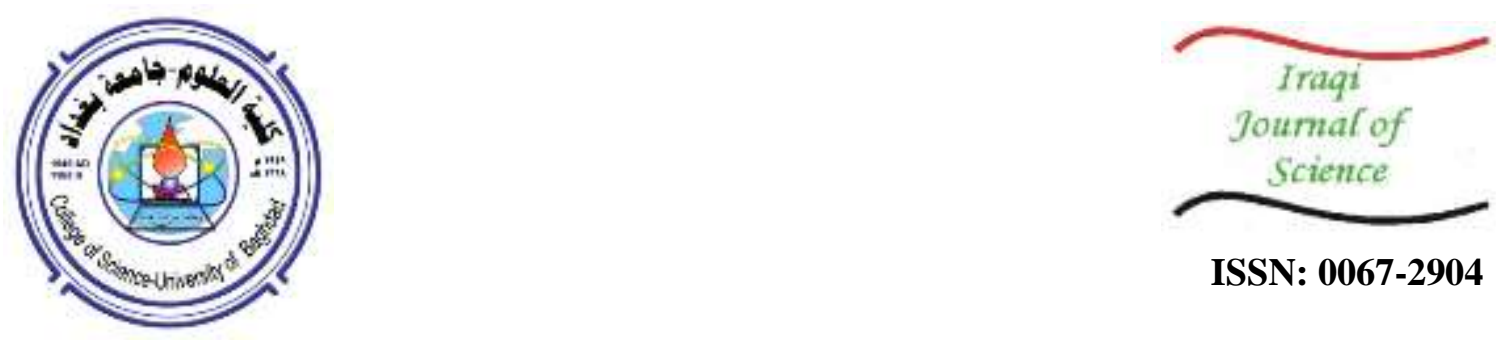

ISSN: 0067-2904

\title{
Determination of Radiation Dose from Routine X-ray Examination at Three Selected Hospitals in AlNajaf, Iraq
}

\author{
Hussien Abid Ali Bakir, Talib A. Abdulwahid*, Aymen S. Amran, Aqeel H. Al Zurfi \\ Department of Physics, Faculty of Science, University of Kufa, ALnajif, Iraq
}

\begin{abstract}
People who undertaken different X-ray examinations are already exposed to ionizing radiation which causes biological effects. Therefore assessing the patient radiation dose is a prerequisite element in optimizing the X-ray practice and to avoid the unnecessary radiation dose. The aim of this research is to assess the skin radiation dose for those patients who undertaking routine $\mathrm{X}$-ray examinations in selected three hospitals in Al Najaf city.

Three X-ray units were involved in this experimental study; these were belonging to three hospitals in Al Najaf city-Iraq, namely Al-Sadder teaching hospital, AlHakeem general hospital and Al-Zahraa hospital. Data of exposure parameters (tube potential $(\mathrm{kVp})$, tube current $(\mathrm{mAs})$ and source to detector distance $(\mathrm{d} \mathrm{cm}))$. The data were collected from 160 patients exposed to radiation during different X-ray examinations. Patients were chosen to be within adult range (>18 years) and the selection was random (male and female). Patient skin dose was calculated mathematically using an established formula depending on the recorded exposure factor $(\mathrm{kVp}, \mathrm{mAs}$ and $\mathrm{d})$. Different $\mathrm{X}$-ray examinations were considered, namely skull Posterior -anterior (PA), skull Lateral (LAT), chest PA, chest LAT, abdomen Anterior-posterior (AP), pelvis AP, lumbar spine AP and lumbar LAT. The average skin dose for all X-ray examinations considered in this research were as follow: 0.9, $0.76,0.23,0.41,1.85,1.82,2.03$ and $3.44 \mathrm{mGy}$, for skull PA, skull LAT, chest PA, chest LAT, abdomen AP, pelvis AP, lumbar spine(LS) AP and Lumbar spine (LS)LAT respectively. The results demonstrate that the dose values were comparable to those that were previously reported in published reference.
\end{abstract}

Keywords: skin dose, X-ray examinations, radiation protection, radiography.
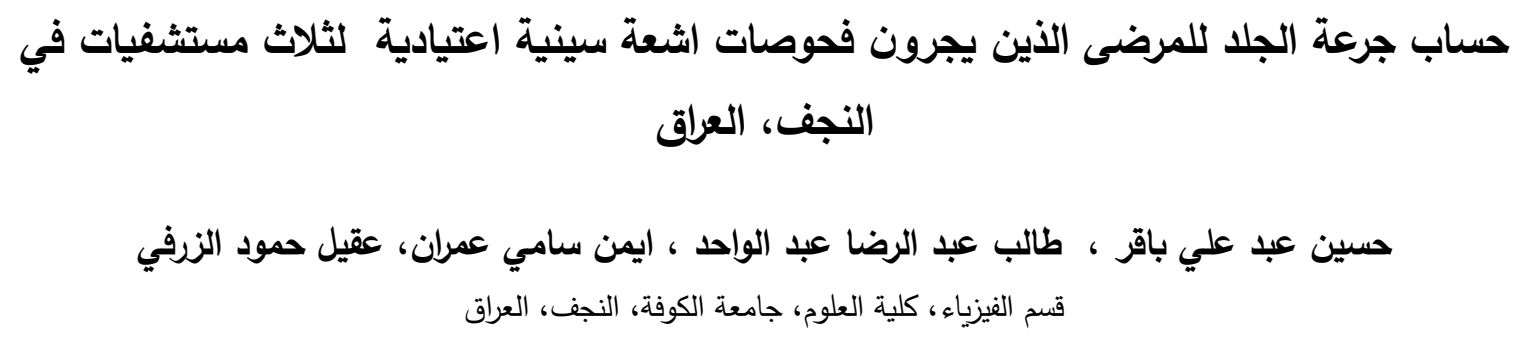

إن المرضى الذين يخضعون لفحوصات الأشعة الينية المختلفة يتعرضون فعليا للإثعاع المؤين ، لذا

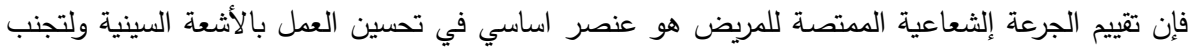

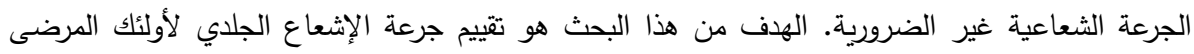

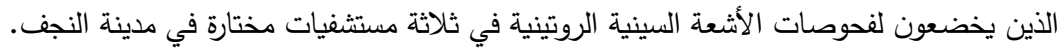

*Email: taliba.jabir@uokufa.edu.iq 


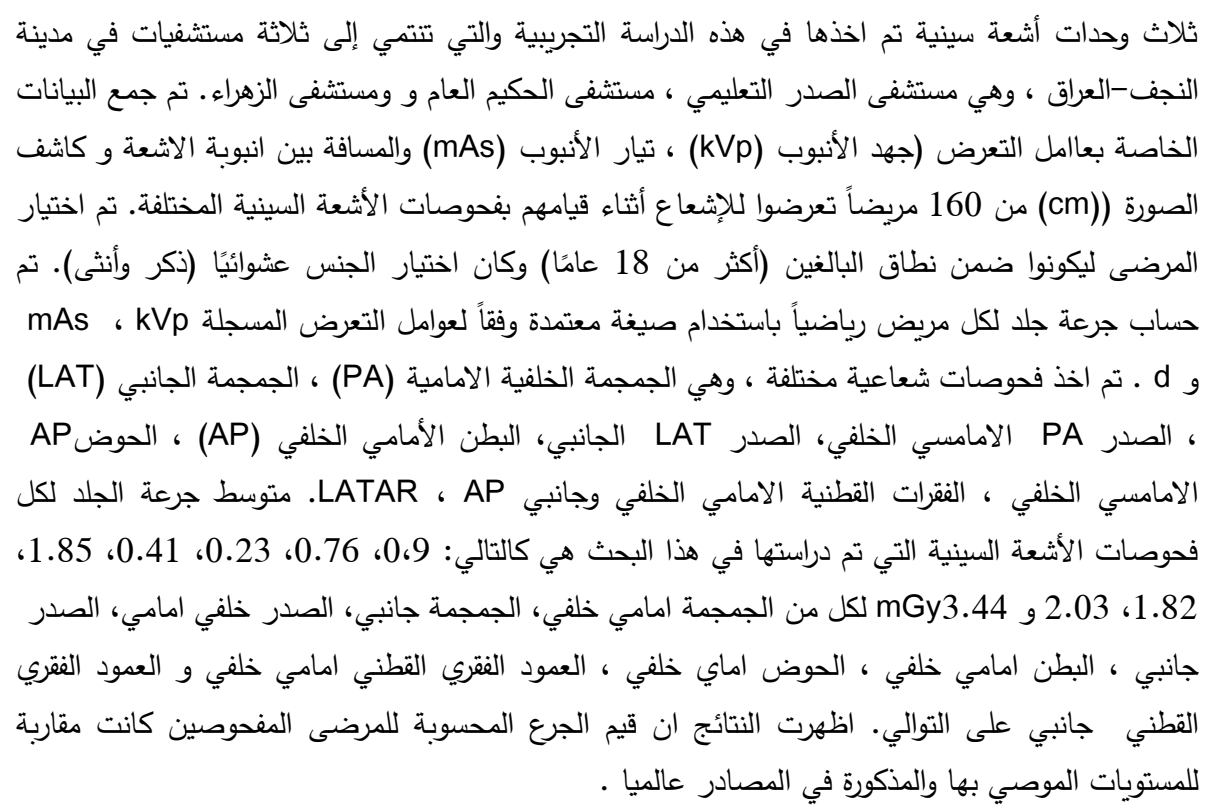

\section{Introduction}

In both developed and developing countries, the number and the range of $\mathrm{X}$-ray facilities and $\mathrm{X}$ ray equipment have been increased rapidly [1]. Although alternative means for diagnosis such as ultrasound and MRI are becoming increasingly available, steady improvement in the quality of X-ray images and patient protection have ensured that diagnostic X-rays remain the most used tool in the diagnosis[2] This reason makes X-ray a major contribution to man's exposure to ionizing radiation from man-made sources. In recent years, health physicists have devoted much effort to minimize a patient dose of radiation in diagnostic radiology [3]. Through these efforts, substantial reductions in radiation dose to patients resulting from radiographic procedures have been achieved in many countries [4].The International Atomic Energy Agency (IAEA) has recommended guidance levels of dose for diagnostic radiography for a typical adult patient. These levels were intended to act as thresholds to trigger investigations or corrective actions in ensuring optimized protection of patients and maintaining appropriate levels of good practice. Since guidance levels should be derived from a wide scale, surveys of exposure factors performed in individual hospitals [5]. Several dose surveys were conducted recently in different countries such as Sudan, Syria, Iran and Saudi Arabia. Some of these studies found the patient doses were comparable to the published international levels, whereas others found it to be higher than the recommended level [6-10].

The aim of this study is to measure patients' surface dose arising from X-ray examinations of the pelvis AP, abdomen AP, skull (PA and LAT), chest(PA and LAT), and lumbar spine (AP and LAT) in three hospitals in Al Najaf city. The result of this study can be used as a reference for radiographic examinations. The patient dose was estimated in the present study in terms of Surface dose.

\section{Material and Methods}

The data were collected from 160 patients with an average mass of $70 \mathrm{~kg}$ at three major hospitals in Al Najaf city, Iraq, which comprising three x-ray units. Radiographic projections studied were: Chest PA/LAT, Lumbar Spine AP/LAT, abdomen AP, Pelvis AP and Skull PA/LAT. For each patient, the following exposure parameters were recorded: peak tube voltage $(\mathrm{kVp})$, exposure current-time product (mAs), and the focus-to-film distance (FFD). These parameters were used in surface dose assessment using the following formula $[11,12]$ :

Surface dose $(\mu \mathrm{Gy})=418(\mathrm{kVp})^{1.74} \times(\mathrm{mAs}) \times\left[(1 / \mathrm{T}+0.114) /(\mathrm{SSD})^{2}\right]$

Where $\mathrm{kVp}$ is the peak voltage which responsible for the quality of penetration, $\mathrm{mAs}$ is the tube current responsible for the quantity of electrons from the filament, $\mathrm{T}$ is the total filtration of the beams $(2.5 \mathrm{mmAl})$ and skin source distance (SSD) where SSD = focal film distance (FFD) - patient thickness. The above equation was formulated into a program using matlab to facilitate the process of mathematical calculations of patients' skin dose and to reduce the error (Figure-1). 


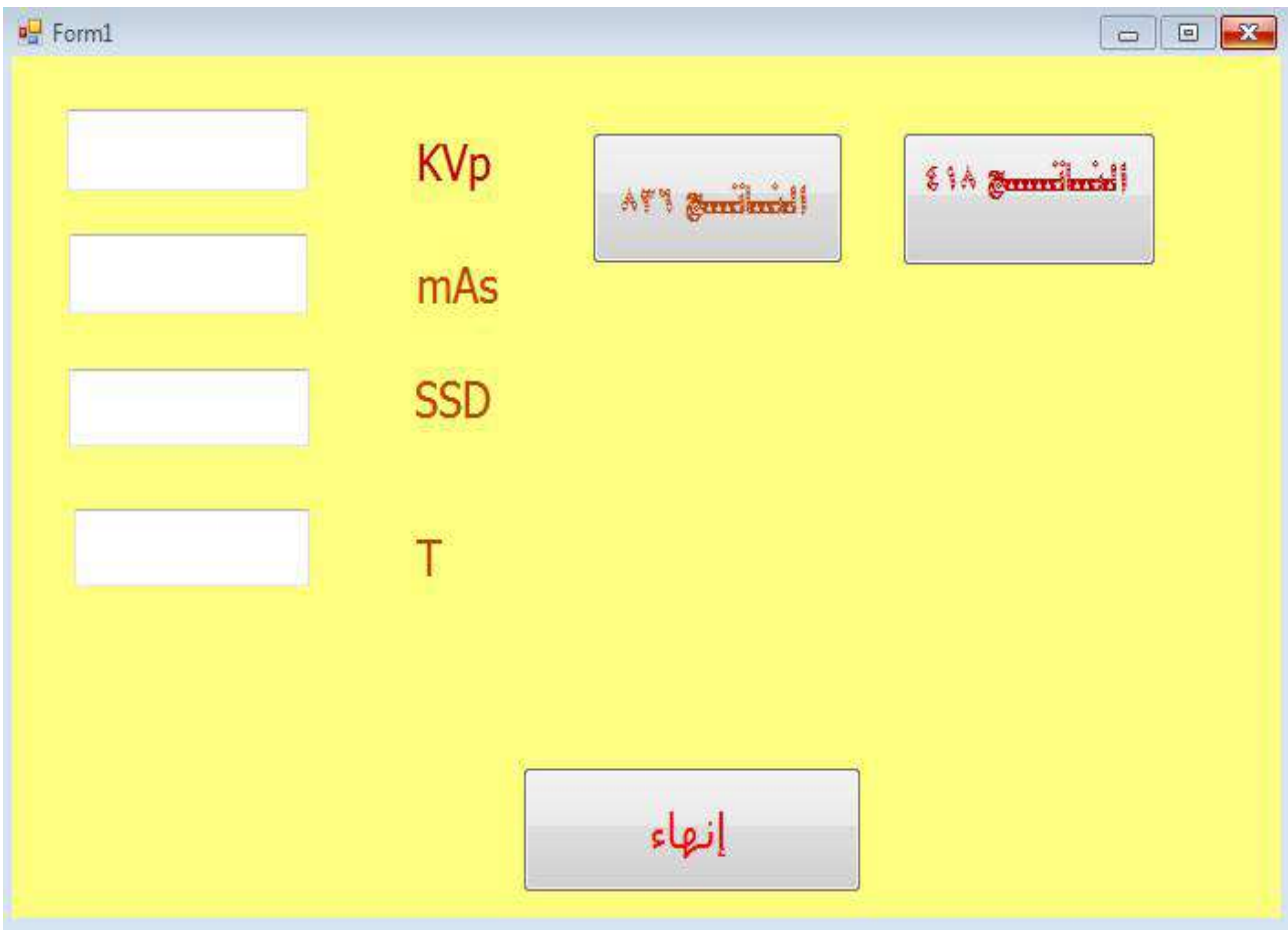

Figure 1-The exposure parameters.

\section{Results}

This work was carried out in three major hospitals in Al Najaf city-Iraq. These hospitals are AlSadder teaching hospital, Al-Hakeem general hospital, and Al-Zahraa hospital. The mean and standard deviation of the exposure factors $(\mathrm{kV}, \mathrm{mAs}, \mathrm{SSD})$ were determined for the following examinations: Skull PA/LAT, Chest PA/LAT, Abdomen AP, Pelvis AP, L-S AP/LAT Tables-(1-4). The weights of the patients were considered.

Table 1-Patient weight and exposure parameters in Al-Sadder teaching Hospital

\begin{tabular}{|c|c|c|c|c|c|c|}
\hline Projection & SSD $(\mathrm{cm})$ & $\begin{array}{c}\text { Miliamper } \\
\text { second(mAs) }\end{array}$ & $\begin{array}{c}\text { Peak Kilovoltage } \\
(\mathrm{kVp})\end{array}$ & $\begin{array}{c}\text { Patient } \\
\text { Weight(kg) }\end{array}$ & $\begin{array}{c}\text { Patient } \\
\text { Hight }(\mathrm{cm})\end{array}$ & Dose(mGy) \\
\hline Skull PA & $85 \pm 0.0$ & $26 \pm 5$ & $72.5 \pm 2.5$ & $77 \pm 15$ & $165 \pm 5$ & $1.33 \pm 0.10$ \\
\hline Skull LAT & $90 \pm 0.0$ & $2.25 \pm 0.25$ & $77.5 \pm 7.5$ & $77 \pm 15$ & $165 \pm 5$ & $1.15 \pm 0.07$ \\
\hline Chest PA & $160 \pm 0.0$ & $2 \pm 0$ & $77.5 \pm 2.5$ & $77 \pm 19$ & $166.6 \pm 1.5$ & $0.33 \pm 0.03$ \\
\hline Chest LAT & $154 \pm 0.0$ & $1.75 \pm 0.75$ & $80 \pm 10$ & $77 \pm 19$ & $182.5 \pm 2.5$ & $0.32 \pm 0.05$ \\
\hline abdomen AP & $80 \pm 0.0$ & $28.5 \pm 3.5$ & $87.5 \pm 7.5$ & $77 \pm 15$ & $168.5 \pm 13.5$ & $2.2 \pm 0.28$ \\
\hline Pelvis AP & $80 \pm 0.0$ & $22 \pm 2.5$ & $82.5 \pm 7.5$ & $75 \pm 14$ & $170 \pm 13$ & $1.6 \pm 0.25$ \\
\hline LS AP & $80 \pm 0.0$ & $29 \pm 4$ & $87.5 \pm 4$ & $74 \pm 17$ & $171.5 \pm 11.5$ & $2.3 \pm 0.46$ \\
\hline LS LAT & $80 \pm 0.0$ & $3 \pm 1$ & $120 \pm 5$ & $74 \pm 17$ & $175 \pm 8$ & $4.1 \pm 0.77$ \\
\hline
\end{tabular}

Table 2-Patient weight and exposure parameters in Al-Zahraa hospital

\begin{tabular}{|c|c|c|c|c|c|c|}
\hline Projection & SSD $(\mathrm{cm})$ & $\begin{array}{c}\text { Miliamper } \\
\text { second(mAs) }\end{array}$ & $\begin{array}{c}\text { Peak Kilovoltage } \\
(\mathrm{kVp})\end{array}$ & $\begin{array}{c}\text { Patient } \\
\text { Weight }(\mathrm{kg})\end{array}$ & $\begin{array}{c}\text { Patient } \\
\text { Hight(cm) }\end{array}$ & Dose(mGy) \\
\hline Skull PA & $85 \pm 0.0$ & $15 \pm 3$ & $68 \pm 5$ & $74 \pm 9$ & $180 \pm 5$ & $0.7 \pm 0.41$ \\
\hline Skull LAT & $90 \pm 0.0$ & $16 \pm 3$ & $68 \pm 4$ & $73 \pm 8$ & $180 \pm 5$ & $0.63 \pm 0.37$ \\
\hline Chest PA & $160 \pm 0.0$ & $13 \pm 1$ & $72 \pm 5$ & $74 \pm 9$ & $175 \pm 3$ & $0.1 \pm 0.08$ \\
\hline
\end{tabular}




\begin{tabular}{|c|c|c|c|c|c|c|}
\hline Chest LAT & $154 \pm 0.0$ & $25 \pm 3$ & $82 \pm 4$ & $72 \pm 8$ & $175 \pm 3$ & $0.48 \pm 0.67$ \\
\hline abdomen AP & $80 \pm 0.0$ & $21 \pm 6$ & $81 \pm 7$ & $74 \pm 10$ & $168 \pm 6$ & $1.47 \pm 1.29$ \\
\hline Pelvis AP & $80 \pm 0.0$ & $37 \pm 2$ & $81.8 \pm 8$ & $73 \pm 8$ & $179 \pm 4$ & $2.6 \pm 1.83$ \\
\hline LS AP & $80 \pm 0.0$ & $27 \pm 8$ & $85 \pm 7$ & $73 \pm 8$ & $174 \pm 2$ & $2.06 \pm 2.70$ \\
\hline LS LAT & $80 \pm 0.0$ & $35 \pm 8$ & $94 \pm 5$ & $73 \pm 8$ & $174 \pm 2$ & $3.17 \pm 2$ \\
\hline
\end{tabular}

Table 3-Patient weight and exposure parameters in Al Hakeem general hospital

\begin{tabular}{|c|c|c|c|c|c|c|}
\hline Projection & SSD $(\mathrm{cm})$ & $\begin{array}{c}\text { Mili amper } \\
\text { second(mAs) }\end{array}$ & $\begin{array}{c}\text { Peak Kilovoltage } \\
(\mathrm{kVp})\end{array}$ & $\begin{array}{c}\text { Patient } \\
\text { Weight }(\mathrm{kg})\end{array}$ & $\begin{array}{c}\text { Patient } \\
\text { Hight(cm) }\end{array}$ & Dose(mGy) \\
\hline Skull PA & $85 \pm 0.0$ & $19 \pm 4$ & $68 \pm 3$ & $58 \pm 9$ & $178 \pm 3$ & $0.8 \pm 0.11$ \\
\hline Skull LAT & $90 \pm 0.0$ & $16 \pm 2$ & $63 \pm 2$ & $65 \pm 11$ & $178 \pm 3$ & $0.5 \pm 0.04$ \\
\hline Chest PA & $160 \pm 0.0$ & $18 \pm 2$ & $66 \pm 4$ & $59 \pm 17$ & $180 \pm 1$ & $0.2 \pm 0.03$ \\
\hline Chest LAT & $154 \pm 0.0$ & $23.3 \pm 2.6$ & $79 \pm 6$ & $81 \pm 5$ & $180 \pm 1$ & $0.42 \pm 0.05$ \\
\hline Abdomen AP & $80 \pm 0.0$ & $27 \pm 5$ & $77 \pm 5$ & $71 \pm 13$ & $176 \pm 4$ & $1.73 \pm 0.29$ \\
\hline Pelvis AP & $80 \pm 0.0$ & $24 \pm 4$ & $75 \pm 4$ & $68 \pm 13$ & $169 \pm 2$ & $1.47 \pm 0.19$ \\
\hline LS AP & $80 \pm 0.0$ & $27 \pm 4$ & $78 \pm 4$ & $69 \pm 8$ & $182 \pm 3$ & $1.77 \pm 0.20$ \\
\hline LS LAT & $80 \pm 0.0$ & $40 \pm 1$ & $88 \pm 4$ & $69 \pm 8$ & $182 \pm 3$ & $3.2 \pm 0.32$ \\
\hline
\end{tabular}

Table 4-Shows mean skin dose (mGy) for all hospitals included in this study compared with IAEA \&NRPB \&CEC recommended guidance level .

\begin{tabular}{|c|c|c|c|c|c|}
\hline Projection & $\begin{array}{c}\text { Reference } \\
\text { Dose[13] }\end{array}$ & $\begin{array}{c}\text { Al Hakeem } \\
\text { Hospital Dose }\end{array}$ & $\begin{array}{c}\text { Al-Zahraa } \\
\text { Hospital Dose }\end{array}$ & $\begin{array}{c}\text { Al-Sadder } \\
\text { Hospital Dose }\end{array}$ & $\begin{array}{c}\text { Average of the } \\
\text { Hospitals }\end{array}$ \\
\hline Skull PA & 2.0 & 0.8 & 0.7 & 1.33 & 0.9433 \\
\hline Skull LAT & 2.0 & 0.5 & 0.63 & 1.15 & 0.76 \\
\hline Chest PA & 0.2 & 0.2 & 0.1 & 0.33 & 0.21 \\
\hline Chest LAT & 0.7 & 0.42 & 0.48 & 0.32 & 0.466 \\
\hline Abdomen AP & 4.0 & 1.73 & 1.47 & 2.2 & 1.8 \\
\hline Pelvis AP & 1.5 & 1.47 & 2.6 & 1.6 & 1.89 \\
\hline LS AP & 3.0 & 1.77 & 2.06 & 2.3 & 2.0433 \\
\hline LS LAT & 3.0 & 3.2 & 3.17 & 4.1 & 3.44 \\
\hline
\end{tabular}

\section{Discussion}

In this study $\mathrm{kVp}$, mAs and SSD were ranged from (63-120) $\mathrm{kVp}$, (1.754-40) $\mathrm{mAs}$ and (80-160) $\mathrm{cm}$, respectively. The surface dose at (Al-Sadder hospital) was the highest and for all X-ray examinations and this may due to the high tube output of the machine combined with low tube filtration [14]. For Skull (PA\&LAT) all values were below the IAEA recommended level. In LS (LAT) examinations, all hospitals showed that the surface dose values were higher than the IAEA reference dose. This could be attributed to the relatively high exposure parameters used in these hospitals [15]. It is also possible that the skills and the experience of the radiographers had certain effect on the resulted patients' doses [16]. Similar reason can be made for other hospitals where high surface dose values were observed, to lower the dose, radiographers should decrease either the tube potential or the tube voltage or both when no impact on the image quality is observed. Also, one can keep the tube potential and tube loading constant while altering the distance taking advantage of the inverse square law. In general, all values of surface dose in this study within the IAEA recommendation in spite of a slight increase in some cases.

The high doses can be attributed to the relatively higher X-ray tube parameters used. In examinations (Skull PA/LAT, Chest PA/LAT, Abdomen AP, Pelvis AP and L/S AP/LAT), the highest 
values of the surface dose for LA LAT were found to be around $4.1 \mathrm{mGy} \pm 0.77$ in Al-Sadder hospital, 3.17 in Al-Zahraa hospital and 3.2 in Al-Hakeem general hospital. The variations in results of the three hospitals, as reflected in the range values, were partially due to variations in patient size and used technique. The highest tube potentials used were reported in Al-Sadder teaching hospital for LS-LAT $(120 \mathrm{kVp})$.

\section{Conclusions}

Radiation dose for the patient who undertaken chest (PA and LAT), skull (AP and LAT), abdomen (AP), pelvis (AP) and LS (AP and LAT) examinations in three hospitals in Najaf were determined. The individual skin dose values were observed to be consistent with the range of values that were reported in other studies with some slight decrease and increase in certain value at certain radiological positions. The mean values of the present study were comparable with reference levels in literature.

\section{Acknowledgement:}

I would like to thank all the staff working in radiology department at all hospitals considered in this study at Al- Najaf city for their cooperation and assistance to achieve this study.

\section{References}

1. United Nations Scientific Committee on the Effects of Atomic Radiation. 2000. Sources and Effects of Ionizing Radiation. Report to the General Assembly with scientific annexes.

2. Muhogora W.E. and Nyanda A.M. 2001.The potential for reduction of radiation doses to patients undergoing some common X ray examinations in Tanzania, Radiat Prot Dosim, 94: 381-4.

3. International Commission on Radiological Protection. 1991. Recommendations of the International Commission on Radiological Protection. ICRP Publication 60. Oxford: Pergamon Press.

4. Martin C.J., Sharp P.F. and Sutton D.G. 1999. Measurement of image quality in diagnostic radiology, App Radiat Isot, 50: 21-38.

5. International Atomic Energy Agency (IAEA). 2007. Dosimetry in diagnostic radiology: an international code of IAEA. Technical report series No.457, Vienna: IAEA.

6. Taha M.T., Al-Ghorabie F.H., Kutbi R.A. and Saib W.K. 2015.Assessment of Entrance Skin Doses for Patients Undergoing Diagnostic X-ray Examinations in king Abdulla medical city, Makkah, KSA, Journal of Radiation Research and Applied Science, 8: I00-I03.

7. Rasuli B., Pashazadeh A.M., Ghorbani M., Juybari R.T. and Naserpour M. 2016. Patient dose measurement in common medical X-ray examinations in Iran, Journal of applied clinical medical physics ,17(1): 374-386.

8. Suliman I.I., Abbas N. and Habbani, F.I. 2007. Entrance surface doses to patients undergoing selected diagnostic X-ray examinations in Sudan, Radiation Protection Dosimetry, 123(2):209214.

9. Kharita, M.H., Khedr, M.S. and Wannus, K. M. 2010. Survey of patient doses from conventional diagnostic radiographic examinations in Syria, Radiation Protection Dosimetry, 140(2): 163-165.

10. Tolga, I. and Atac G. 2014. Dose audit for patients undergoing two common radiography examinations with digital radiology systems, Diagn Interv Radiol, 20: 100-4.

11. Mraity, H.A. 2008. Estimation of surface dose (skin absorbed dose) for the patient undergoing standards radiologic examinations, Journal of Kerbala University, 6: 260-259.

12. Edmonds, I.R. 1984. Calculation of patient skin dose from diagnostic X-ray procedures, the British Journal of radiology, 57(680): 733-734.

13. International Atomic Energy Agency (IAEA).1996. International basic safety standard for protection against ionizing radiation and for the safety radiation sources. IAEA Safety Series No. 115, Vienna: IAEA.

14. Bushong, S. C. 2013. Radiologic science for technologists physics, biology and protection. Third Edition .Missouri, Mosby.

15. Fauber, T. L. 2014. Radiographic imaging and exposure. Fourth Edition. Missouri, Mosby.

16. Carroll, Q. B. 2007. Practical radiographic imaging. Eighth Edition. Charles C. Thomas . 